\title{
A Rare Form of Lichenoid Tissue Reaction: Lichenoid Granulomatous Dermatitis
}

\author{
Isil Bulura, e, Hilal Gokalp ${ }^{\mathrm{b}}$, Ozlem Erdem ${ }^{\mathrm{c}}$, Mehmet Ali Gurer ${ }^{\mathrm{d}}$
}

\begin{abstract}
Interface dermatitis is characterized by inflammatory infiltration dermoepidermal junction and defined as lichenoid tissue reaction. This histopathological appearance and pathophysiological process are mainly observed in lichen planus, lichenoid drug reaction, lichenoid autoimmune connective tissue disease, lichenoid purpura and lichenoid granulomatosis dermatitis. In this case, we report a 51-yearold female patient, diagnosed with lichenoid granulomatous dermatitis concurrence with myasthenia gravis and thymoma.
\end{abstract}

Keywords: Lichenoid; Granulom; Dermatit

\section{Introduction}

Lichenoid granulomatous dermatitis is a rare interface dermatitis which is histopathologically characterized by a band-like lymphocytic infiltrate in the epidermis and dermoepidermal junction and accompanied by variable degenerative epithelial alteration. It may be associated with hepatobiliary diseases, endocrinopathies, Crohn's disease, infections and drugs [1]. The most common clinical presentation of the disease is lichen planus, lichen nitidus and lichen striatus [2]. We present a case diagnosed histopathologically with lichenoid granulomatous dermatitis with severe skin involvement accompanied by myasthenia gravis and thymoma.

Manuscript accepted for publication January 05, 2015

aDepartment of Dermatology and Venereology, Osmangazi University Faculty of Medicine, Eskisehir, Turkey

bepartment of Dermatology and Venereology, Koc University Faculty of Medicine, Istanbul, Turkey

${ }^{\mathrm{c}}$ Department of Pathology, Gazi University Faculty of Medicine, Ankara, Turkey

dDepartment of Dermatology and Venereology, Gazi University Faculty of Medicine, Ankara, Turkey

eCorresponding Author: Isil Bulur, Department of Dermatology and Venerology, Osmangazi University Faculty of Medicine, Eskisehir, Turkey.

Email: isilbulur@yahoo.com

doi: http://dx.doi.org/10.14740/jmc2031w

\section{Case Report}

A 51-year-old female patient presented at our clinic with purple-red lesions on the body and skin induration. The history of the patient revealed that her complaints had started 5 years ago with purple lesions on the hands and arms. The patient was treated with neotigason $25 \mathrm{mg} /$ day, d-UVB and PUVA at an external center with a diagnosis of lichen planus, but she expressed that she had not benefited from these treatments. There was nothing of significance in her personal and family history. Dermatological examination revealed diffuse hypo-hyperpigmented sclerotic plaques, purple papules and plaques on the hand dorsum and body, white fibrinated plaques with irregular borders on the right buccal mucosa, scared alopecia areas with irregular borders on the scalp (Fig. 1). Full blood count and biochemical examinations were within normal limits. ANA and anti-ds DNA were (-), anticholinesterase was (+), while anti-Jo-1, anti-Sm, anti-SCL-70, anti-SS-A, anti-SS-B, and anti-RNP were all within normal limits. During concomitant systemic evaluation, thymoma and myasthenia gravis were diagnosed.

Microscopic examination of the purple plaques was characterized by interface changes and lichenoid inflammation (Fig. 2A). Histopathology of the sclerotic plaques revealed mild hyperkeratosis on the surface of the epidermis; vacuolar degeneration, rare necrotic keratinocytes and lymphocyte exocytosis in the dermoepidermal junction; and significant coarsening of collagen fibers and eosinophilic homogeneous appearance in the superficial dermis under the epidermis. Noncaseating granulomas with few multinucleated giant cells in the reticular dermis were identified (Fig. 2B).

The diagnosis of lichenoid granulomatous dermatitis was made clinically and histopathologically. The patient refused any surgery for thymoma, so pyridostigmine bromide (Mestinon $^{\circledR}$ ) qds and prednisolone (Deltocordil ${ }^{\circledR}$ ) $25 \mathrm{mg} /$ day were started by neurology department and we added UVA1 treatment.

\section{Discussion}

Lichenoid granulomatous dermatitis is a rare form of interface dermatitis. It is characterized by a band-like infiltration con- 

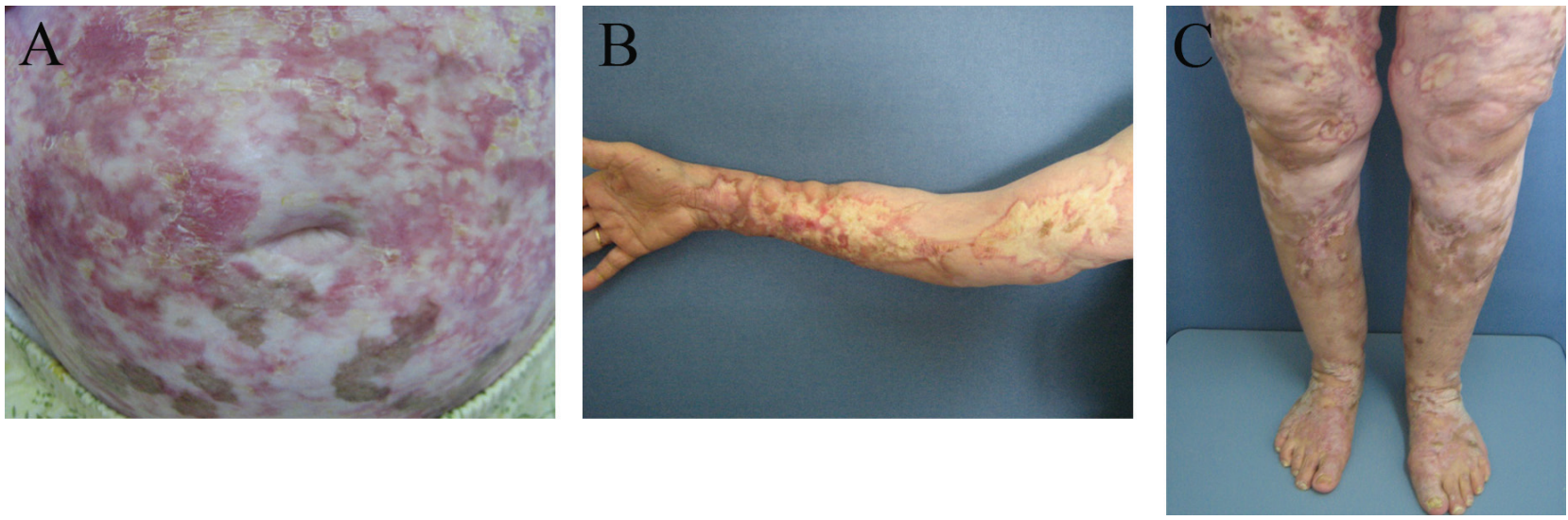

Figure 1. (A) Hypo-hyperpigmented sclerotic plaques on the abdomen; (B) hypo-hyperpigmented sclerotic plaques on the right arm; (C) hypo-hyperpigmented sclerotic plaques on the legs.

sisting of lymphocytes and histiocytes in the epidermis and dermoepidermal junction on histopathological examination. In addition, parakeratosis, keratinocyte necrosis, acrosyringeal infiltration, lichenoid purpura-like pattern can be observed together with eosinophilia and plasmacellular infiltration in drug-related cases [1]. It may be accompanied by degenerative epithelial changes in the form of vasculopathy, dyskeratosis, and colloid body formation. Histiocytic infiltration can be seen as one of five patterns: 1) superficially disposed, loose small histiocytic aggregates amidst a band-like lymphocytic infiltrate; 2) small epithelioid granulomata within and subjacent to the areas of band-like lymphocytic infiltration; 3) an interstitial array between collagen fibers reminiscent of interstitial granuloma annulare (GA); 4) scattered singly disposed Langhans and/or foreign body type giant cells; and 5) granulomatous vasculitis [1-4]. Histopathologic features in our case were consisted with second type of histiocytic infiltration.

A review of the literature reveals the patients who had been diagnosed with histopathological lichenoid granulomatous dermatitis presenting with a clinical picture similar to lichen planus, lichen striatus, lichen nitidus, drug eruption, erythroderma, necrobiosis lipoidica, psoriasis, granulomatous dermatitis, cutaneous T-cell lymphoma, tinea capitis, pityriasis lichenoides, secondary syphilis or tuberculoid leprosy [1]. The lesions may be generalized or localized $[2,5-7]$. Our case is very special as it shows lichenoid granulomatous dermatitis specifications at histopathological findings with diffuse sclerotic plaques, purple papules and plaques on all over the body.

Lichenoid granulomatous dermatitis can be observed in relation to hepatobiliary diseases, rheumatoid arthritis, endocrinopathies, Crohn's disease, autoimmune diseases, infections and drugs $[1,2,5]$. This type of infiltration may also develop as an idiopathic response against active infection or microbial antigens [1].

The relationship between thymoma and lichen planus has been linked to the increase of TNF- $\alpha$ and metalloproteinase secretion following the reaction between specific autoreactive T-lymphocyte clones and specific keratinocyte antigens [8]. Seneschal et al evaluated case reports and emphasized the importance of autoimmunity, stating that the association with other disorders was not random [9]. In light of the literature, we believe that autoimmune processes could be responsible for
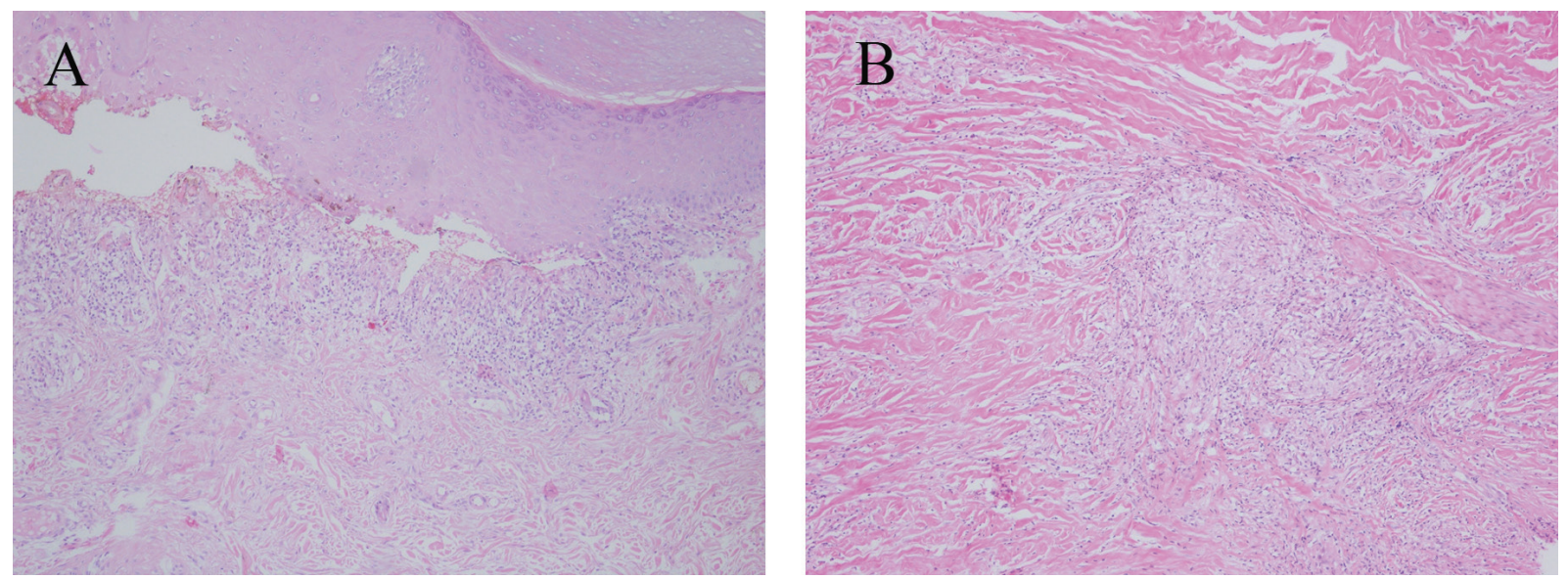

Figure 2. (A) Interface changes and lichenoid inflamation (H\&E, $\times 200)$; (B) non-caseating granulomas located in reticular dermis $(H \& E, \times 200)$. 
the disease severity and the association of myasthenia gravis and thymoma in our case.

\section{Funding Source}

None.

\section{Conflicts of Interest}

None declared.

\section{References}

1. Magro CM, Crowson AN. Lichenoid and granulomatous dermatitis. Int J Dermatol. 2000;39(2):126-133.

2. S. Breza T J, Magro CM. Lichenoid and granulomatous dermatitis associated with atypical mycobacterium infections. J Cutan Pathol. 2006;33(7):512-515.

3. Sehgal VN, Srivastava G, Sharma S, Sehgal S, Verma P. Lichenoid tissue reaction/interface dermatitis: recognition, classification, etiology, and clinicopathological overtones. Indian J Dermatol Venereol Leprol.
2011;77(4):418-429; quiz 430.

4. Crowson AN, Magro CM, Mihm MC, Jr. Interface dermatitis. Arch Pathol Lab Med. 2008;132(4):652-666.

5. Wolf IH, Smolle J, Cerroni L, Kerl H. Erythroderma with lichenoid granulomatous features induced by erythropoietin. J Cutan Pathol. 2005;32(5):371-374.

6. Robinson CM, Oxley JD, Weir J, Eveson JW. Lichenoid and granulomatous stomatitis: an entity or a non-specific inflammatory process? J Oral Pathol Med. 2006;35(5):262-267.

7. Abbas O, Marrouch N, Kattar MM, Zeynoun S, Kibbi AG, Rached RA, Araj GF, et al. Cutaneous non-tuberculous Mycobacterial infections: a clinical and histopathological study of 17 cases from Lebanon. J Eur Acad Dermatol Venereol. 2011;25(1):33-42.

8. Hanafusa T, Umegaki N, Yamaguchi Y, Katayama I. Good's syndrome (hypogammaglobulinemia with thymoma) presenting intractable opportunistic infections and hyperkeratotic lichen planus. J Dermatol. 2010;37(2):171174.

9. Seneschal J, Orlandini V, Duffau P, Viallard JF, Pellegrin JL, Doutre MS, Beylot-Barry M. Oral erosive lichen planus and Good's syndrome: just a coincidence or a direct link between the two diseases? J Eur Acad Dermatol Venereol. 2008;22(4):506-507. 